\title{
Internet: Friend and Foe
}

\author{
Charles Cornell, MD
}

Received: 13 April 2018/Accepted: 13 April 2018/Published online: 9 May 2018

(C) Hospital for Special Surgery 2018

Welcome to the current issue of our Journal, in which several articles emphasize the shoulder and address topics of current interest to this subspecialty. I particularly recommend the article by Werner and his colleagues, in which they address the unexpected risks that may be encountered in patients who have bariatric surgery after total shoulder arthroplasty, including increased rates of periprosthetic instability and loosening. Similar investigations have been undertaken in patients who have bariatric surgery either before or after total hip or knee arthroplasty. An emerging body of literature increasingly suggests that bariatric surgery does not reverse many of the risks of surgery in obese patients and that bariatric surgery may result in nutritional abnormalities that negatively affect surgical outcomes. The article by Werner and his colleagues is an important read for all.

I also direct you to the study by Lyman and his coauthors. Whether or not clinicians are active on the Internet, our online reputations are steadily growing in exposure and importance. This has increasing implications for how the public perceives us, including past and prospective patients, as well as many observers whom we would not typically consider. This online exposure may impact not only our future practice and ability to secure employment but also our social or professional relationships. Lyman and co-authors suggest that surgeons' online reputations may depend on assessments that many of us would not consider the most important ones in evaluating our worth as clinicians.

This article reinforces for me how we all must be familiar with our online presence. We must be cautious about what we disclose, especially as social media are now the predominant venue for advertising and marketing. I suggest we need to be more proactive in managing and protecting our online reputations with the help of our hospitals, business associations, and professional societies.

I hope you enjoy this entire issue. HSS Journal ${ }^{\circledR}$ is clearly gaining in reputation as the place to publish your work in our field. We will continue to strive to improve our Journal's impact as a trusted, multidisciplinary venue for advancing the science of musculoskeletal medicine.

\section{Compliance with Ethical Standards}

Conflict of Interest: Charles Cornell, MD, declares that he has no conflicts of interest.

Required Author Forms Disclosure forms provided by the authors are available with the online version of this article.

Electronic supplementary material The online version of this article (https://doi.org/10.1007/s11420-018-9615-7) contains supplementary material, which is available to authorized users.

C. Cornell, MD ( $\square)$

Hospital for Special Surgery,

535 East 70th Street,

New York, NY 10021, USA

e-mail: cornellc@hss.edu 